\title{
Efeito do Tratamento com Hidróxido de Sódio sobre a Fração Fibrosa, Digestibilidade e Tanino do Feno de Jurema-Preta (Mimosa tenuiflora. Wild) ${ }^{1}$
}

\section{José Morais Pereira Filho2, 3 , Ednéia de Lucena Vieira², Aderbal Marcos de Azevedo Silva², Marcílio Fontes Cezar², Francisco Uchoa Amorim²}

\begin{abstract}
RESUMO - O experimento foi conduzido com o objetivo de avaliar o efeito do tratamento com hidróxido de sódio (NaOH) na fração fibrosa, no teor de tanino e na digestibilidade in vitro da matéria seca do feno de jurema-preta. As folhas foram colhidas manualmente e desidratadas à sombra. $\mathrm{O}$ tratamento químico consistiu na pulverização do feno com solução de $0 ; 2 ; 4 ; 6$ e $8 \%$ de $\mathrm{NaOH}$, na proporção de 1 litro da solução para $1 \mathrm{~kg}$ de feno. Amostras do feno foram submetidas à determinação da matéria seca (MS), proteína bruta (PB), fibra em detergente neutro (FDN), fibra em detergente ácido (FDA), tanino e digestibilidade in vitro da matéria seca (DIVMS), que se constituíram nas variáveis analisadas. O delineamento foi o inteiramente casualizado, com cinco tratamentos e quatro repetições. $\mathrm{O}$ tratamento com $\mathrm{NaOH}$ proporcionou efeito linear decrescente nos teores de MS, hemicelulose e tanino, enquanto, para FDN e FDA, ocorreu efeito quadrático. A PB não foi afetada e a DIVMS melhorou com o aumento da concentração de NaOH. A estimativa da DIVMS pelo teor de tanino, apesar de significativa, carece de mais estudos.
\end{abstract}

Palavras-chave: fibra em detergente ácido, fibra em detergente neutro, leguminosa, $\mathrm{NaOH}$

\section{Effect of Sodium Hydroxide Treatment on Fiber Fraction, Digestibility and Tannin of Jurema-Preta Hay (Mimosa tenuiflora. Wild)}

\begin{abstract}
Experiment was carried out with the goal to evaluate the effect of sodium hydroxide $(\mathrm{NaOH})$ on fiber fraction, tannin level and dry matter in vitro digestibility of jurema-preta hay. Leaves were harvested by hand and dried under shadow. Chemical treatment was done by pulverization of hay with $0 ; 2 ; 4 ; 6$ and $8 \% \mathrm{NaOH}$ solution following the proportion of 1 liter of solution to $1 \mathrm{~kg}$ of hay. Samples of hay were submitted to determinations of dry matter (DM), crude protein (CP), neutral detergent fiber (NDF), acid detergent fiber (ADF), tannin and DM in vitro digestibility which were the variables analyzed. Design completely randomized was used with five treatments and four repetitions. $\mathrm{NaOH}$ treatment caused linear effect in DM, hemicellulose and tannin contents; while for NDF and ADF was observed quadratic effect. CP was not affected and DMIVD was improved by $\mathrm{NaOH}$ concentration increase. DMIVD estimated by tannin content need to be more studied, instead of its significance.
\end{abstract}

Key Words: acid detergent fiber, neutral detergent fiber, legume, $\mathrm{NaOH}$

\section{Introdução}

A jurema-preta é uma leguminosa facilmente encontrada na caatinga, altamente resistente à seca, com grande capacidade de rebrota durante todo o ano e, de acordo com Vieira et al. (1998), caprinos e ovinos apresentaram boa aceitabilidade à juremapreta, seja in natura, seja fenada. Quanto à composição química, Vasconcelos (1997), trabalhando com fenos obtidos nos períodos de março/abril e setembro/outubro, encontrou teores de 90,0 e $90,9 \%$ de MS; 15,1 e 13,5\% de PB; 35, 1 e 36,2\% de FDN; 16,0 e $15,7 \%$ de FDA e 26,6 e $16,9 \%$ de tanino, respectivamente. Embora a jurema-preta seja considerada uma planta forrageira com teor de PB satisfatório, Carvalho Filho \& Salviano (1982) obtiveram na folha in natura valores de DIVMS de apenas $21,81 \%$, resultado atribuído à presença de fatores inibidores da digestibilidade.

Segundo Araújo Filho et al. (1995), o controle de plantas lenhosas e invasoras como a jurema-preta aumentou a disponibilidade de massa seca (MS) pastável na caatinga, possibilitando empreendimentos economicamente viáveis e ecologicamente sustentáveis. Neste contexto, Pereira Filho et al. (1999), trabalhando com caatinga rebaixada e controle da rebrota de jurema-preta, no sertão da Paraíba, obtiveram disponibilidade de MS de folhas de jurema-preta

\footnotetext{
${ }^{1}$ Projeto financiado pelo Banco do Nordeste do Brasil - BNB/FUNDECI.

2 Professor do Departamento de Medicina Veterinária do CSTR/UFPB, Campus VII, Patos - PB. E.mail: jmorais@cstr.ufcg.edu.br; jmpfpiaui@ig.com.br; aderbal@cstr.ufcg.edu.br

${ }^{3}$ Doutorando em Zootecnia e Bolsista da CAPES, FCAV/Unesp, Av. Cândido José Leite, 290, CEP 14.883-352, Jaboticabal - SP. E.mail: jmorais@asbyte.com.br
} 
variando de 227 a $533 \mathrm{~kg}$ MS/ha ano. Os autores destacaram a necessidade de estudos com vistas a melhorar a qualidade nutricional do feno de juremapreta e sugeriram o tratamento químico com hidróxido de sódio como alternativa para aumentar a exposição dos componentes fibrosos à degradabilidade ruminal, e, segundo Jansman (1993), isso pode minimizar os efeitos negativos de fatores antinutricionais, principalmente compostos fenólicos como o tanino.

Os primeiros relatos de uso de tratamento químico para melhorar a digestibilidade de alimentos fibrosos datam de 1881, e vários produtos têm sido testados ao longo dos últimos quarenta anos. Segundo Reis et al. (1995), entre as substâncias mais utilizadas com esse objetivo, estão os hidróxidos de sódio, de potássio e de amônio. Estes autores destacaram a grande eficiência do hidróxido de sódio no tratamento de alimentos fibrosos, porém apresentava a desvantagem de contaminação do ambiente pela excessiva eliminação de sódio na urina e nas fezes dos animais.

A ação dos compostos alcalinos ocorre através da desestruturação dos complexos lignocelulósicos, solubilizando a hemicelulose e aumentando a digestibilidade da celulose pela expansão da fração fibrosa (Jackson, 1977 e Klopfenstein, 1978). As palhadas, restolhos de culturas, bagaço de cana-deaçúcar e fenos de gramíneas de baixo valor nutritivo estão entre os alimentos mais submetidos ao tratamento químico com hidróxido de sódio que, na sua maioria, proporcionam ganhos de 20 a $50 \%$ na digestibilidade in vitro da matéria seca.

Em leguminosas, Reed (1995) verificou que o uso de hidróxido de sódio, além de melhorar a digestibilidade da parede celular, favoreceu a solubilidade de fatores antinutricionais, neutralizando os efeitos inibidores de compostos fenólicos como o tanino. Dessa forma, justifica-se o tratamento com hidróxido de sódio emleguminosas, especialmente as invasoras, como a jurema-preta.

O objetivo deste trabalho foi avaliar o efeito do tratamento químico com hidróxido de sódio na fração fibrosa, no teor de tanino e na digestibilidade in vitro da matéria seca do feno de jurema-preta.

\section{Material e Métodos}

O experimento foi conduzido no Setor de Agrostologia e no Laboratório de Nutrição Animal, do Departamento de Medicina Veterinária, da Universidade Federal da Paraíba, Patos-PB. O clima da região é classificado como quente e seco, caracteri- zado por duas estações bem definidas, uma chuvosa, de janeiro a maio, e outra seca, de junho a dezembro, com médias anuais de $500 \mathrm{~mm}$ de precipitação, $29^{\circ} \mathrm{C}$ de temperatura, $60 \%$ de umidade relativa do ar e altitude de $300 \mathrm{~m}$ acima do nível do mar.

O material utilizado foi obtido em área de caatinga rebaixada, com solos pobres, de drenagem irregular, pH ácido e com vegetação em estádio inicial de sucessão secundária, com três estratos distintos: arbóreo, arbustivo e herbáceo, havendo grande predominância de jurema-preta (Mimosa tenuiflora (Wild.)) e com presença destacada de marmeleiro (Croton sonderianus Muell.Arg.), catingueira (Caesalpinia bracteosa Tul.), mororó (Bauhinia cheilantha (Bong) Stend) e mofombo (Combretum leprosum Mart.).

As folhas de jurema-preta foram colhidas manualmente quando as plantas se encontravam em vegetação plena. O processo de desidratação adotado foi o natural à sombra e o feno obtido, homogeneizado. Os tratamentos químicos consistiram na pulverização (pulverizador manual modelo MS7) do feno com solução de $\mathrm{NaOH}$ nas concentrações de $0 ; 2 ; 4 ; 6$ e $8 \%$, na proporção de um litro da solução para um kg de feno. Ao final de sete dias e para cada tratamento químico, foram feitas amostragens do material para posteriores análises laboratoriais.

As amostras do feno foram submetidas à determinação da matéria seca (MS), proteína bruta (PB), fibra em detergente neutro (FDN), fibra em detergente ácido (FDA), tanino total e digestibilidade in vitro da matéria seca (DIVMS), além da estimativa da hemicelulose. Com exceção do tanino, todas as análises foram obtidas segundo o método descrito por Silva (1998). Para a análise de tanino, foi adotado o método de refluxo com água e reação utilizando o reagente de "Folin-Denis" descrito pela AOAC (1995).

O delineamento experimental utilizado foi o inteiramente casualizado, com as concentrações de $0 ; 2 ; 4 ; 6$; e $8 \%$ de $\mathrm{NaOH}$, constituindo os tratamentos, com quatro repetições. As variáveis analisadas foram os teores de MS, PB, FDN, FDA, tanino total e de hemicelulose, além da DIVMS. Os dados foram submetidos à análise da variância e de regressão pelos procedimentos GLM e REG a 5\% de probabilidade, do pacote estatístico SAS (1999).

\section{Resultados e Discussão}

Os resultados referentes aos efeitos do tratamento químico com hidróxido de sódio nos teores de matéria seca, fibra em detergente neutro, fibra em

\footnotetext{
R. Bras. Zootec., v.32, n.1, p.70-76, 2003
} 
detergente ácido, hemicelulose e proteína bruta, com os respectivos coeficientes de variação e níveis de significância, são apresentados na Tabela 1, enquanto as respectivas equações de regressão e os coeficientes de determinação constam da Tabela 2 .

Observa-se que somente o teor de PB não sofreu influência $(\mathrm{p}>0,05)$ do tratamento com $\mathrm{NaOH}$, fato já esperado, tendo em vista que a ação do $\mathrm{NaOH}$ sobre a deslignificação da hemicelulose e da celulose da parede celular não deve alterar a concentração de PB (concentração de nitrogênio multiplicado por 6,25), diferenciando-se dos tratamentos que utilizam produtos químicos, como a amônia ou a uréia, que incorporam nitrogênio não protéico ao material tratado (Madrid et al., 1998). Qualquer alteração nos teores de PB de feno tratado exclusivamente com $\mathrm{NaOH}$, possivelmente, estaria associada à leve fermentação durante o tratamento (Chaudhry, 1998).

$\mathrm{O}$ teor de matéria seca diminuiu linearmente $(p<0,05)$ com o aumento na concentração de $\mathrm{NaOH}$, verificando-se que o acréscimo de uma unidade de
$\mathrm{NaOH}$ na solução proporcionou queda de 0,273 no percentual de MS. Esta relação pode estar associada ao caráter higroscópico da solução de hidróxido de sódio, proporcionando pequena e gradativa diminuição no teor de matéria seca. Resultado semelhante foi obtido por Moreira et al. (1996), que obtiveram teores de MS de $91,47 \%$ e $89,97 \%$ para o feno de Brachiaria decumbens Stapt submetido à aplicação de solução alcalina contendo concentração de zero e de $4,25 \%$ de $\mathrm{NaOH}$ sobre o total de matéria seca tratada.

A concentração de FDN na MS do feno de juremapreta apresentou comportamento estável até o nível de $2 \%$ de $\mathrm{NaOH}$, mas, ao considerar os efeitos de todos os tratamentos, verificou-se efeito quadrático $(\mathrm{p}<0,05)$, indicando que a utilização de 2 a $8 \%$ de $\mathrm{NaOH}$ proporcionou diminuição no teor de FDN.

O principal efeito do hidróxido de sódio sobre os componentes da parede celular caracteriza-se pela hidrólise alcalina das ligações covalentes do tipo éster entre a lignina e os carboidratos estruturais (Tarkov \& Feist, 1969); desta forma, ocorre a

Tabela 1 - Teores médios de matéria (MS), fibra em detergente neutro (FDN), fibra em detergente ácido (FDA), hemicelulose e proteína bruta (PB) em função dos níveis de hidróxido de sódio $(\mathrm{NaOH})$, no tratamento do feno de jurema-preta, coeficiente de variação $(C V)$ e probabilidade $(P)$ referentes aos efeitos linear $(L)$ e quadrático $(Q)$

Table 1 - Means of dry matter (DM), neutral detergent fiber (NDF), acid detergent fiber (ADF), hemicellulose and crude protein (CP) in function of sodium hydroxide $(\mathrm{NaOH})$ levels in treatment of Jurema-Preta hay, coefficients of variation (CV) and level of probabiliy $(P)$ in relation to the linear $(L)$ and quadratic $(Q)$ effects

\begin{tabular}{|c|c|c|c|c|c|c|c|c|}
\hline \multirow[t]{2}{*}{$\begin{array}{l}\text { Variáveis } \\
\text { Variables }\end{array}$} & \multicolumn{5}{|c|}{$\begin{array}{c}\text { Tratamentos - Níveis de } \mathrm{NaOHCV}(\%) \\
\text { Treatment - NaOH Levels }\end{array}$} & & \multicolumn{2}{|c|}{$\mathrm{P}$} \\
\hline & 0 & 2 & 4 & 6 & 8 & & $\mathrm{~L}$ & Q \\
\hline $\operatorname{MS}(D M)(\%)$ & 91,19 & 90,61 & 90,15 & 90,07 & 88,73 & 0,394 & 0,001 & NS \\
\hline $\mathrm{FDN}^{1}(N D F)$ & 44,48 & 44,03 & 42,02 & 36,33 & 32,78 & 2,037 & NS & 0,001 \\
\hline $\mathrm{FDA}^{1}(A D F)$ & 29,52 & 29,19 & 27,56 & 24,25 & 19,17 & 1,123 & 0,0012 & 0,001 \\
\hline Hemicelulose $^{1}$ & & & & & & & & \\
\hline Hemicellulose & 14,96 & 14,84 & 14,46 & 13,61 & 12,08 & 6,135 & 0,008 & NS \\
\hline $\mathrm{PB}^{1}(C P)$ & 14,36 & 14,33 & 14,64 & 13,32 & 13,88 & 4,694 & NS & NS \\
\hline
\end{tabular}

${ }^{1}$ Porcentagem da MS (DM percentage); NS = não-significativo (not significant).

Tabela 2 - Equações de regressão para matéria (MS), fibra em detergente neutro (FDN), fibra em detergente ácido (FDA) e hemicelulose, em função dos níveis de hidróxido de sódio $(\mathrm{NaOH})$, no tratamento do feno de jurema-preta, e coeficiente de determinação $\left(R^{2}\right)$

Table 2 - Regression equations for dry matter (DM), neutral detergent fiber (NDF), acid detergent fiber (ADF) and hemicellulose in function of sodium hydroxide $(\mathrm{NaOH})$ levels in the treatment of jurema-preta hay and coefficients of determination $\left(r^{2}\right)$

\begin{tabular}{lcc}
\hline $\begin{array}{l}\text { Variáveis } \\
\text { Variables }\end{array}$ & $\begin{array}{l}\text { Regressão } \\
\text { Regression }\end{array}$ & $\mathrm{R}^{2} / \mathrm{r}^{2}$ \\
\hline $\mathrm{MS}(D M)(\%)$ & $\mathrm{Y}=-0,273 * \mathrm{X}+91,246$ & 0,841 \\
$\mathrm{FDN}^{1}(N D F)$ & $\mathrm{Y}=-0,176^{*} \mathrm{X}^{2}-0,143 * \mathrm{X}+44,735$ & 0,974 \\
$\mathrm{FDA}^{1}(A D F)$ & $\mathrm{Y}=-0,199^{*} \mathrm{X}^{2}+0,314 * \mathrm{X}+29,468$ & 0,995 \\
Hemicelulose $^{1}$ (Hemicellulose) & $\mathrm{Y}=-0,273^{*} \mathrm{X}+15,082$ & 0,473 \\
\hline
\end{tabular}

${ }^{1}$ Porcentagem da MS (DM percentage).

R. Bras. Zootec., v.32, n.1, p.70-76, 2003 
solubilização da hemicelulose (Chaudhry, 2000) e de compostos fenólicos (Kerley et al., 1987) com a conseqüente diminuição no teor de FDN. Em geral, em todos os trabalhos avaliados e que faziam referências à ação do $\mathrm{NaOH}$ nos componentes da parede celular, os resultados obtidos foram semelhantes, destacando-se Andrade et al. (2001), que trabalharam com cana-de-açúcar, e Moreira et al. (1996), que avaliaram feno da gramínea Brachiaria decumbens Stapt.

Houve efeito quadrático $(\mathrm{p}<0,05)$ do tratamento químico no teor de FDA do feno de jurema-preta, semelhantemente ao que ocorreu com a FDN. Muitos trabalhos ilustram que o uso de $\mathrm{NaOH}$ em alimentos fibrosos não diminui (Manzano et al., 2000), e também não aumenta (Chaudhry, 1998) os teores de FDA. Já no trabalho de Nolte et al. (1987), foi obtido decréscimo de FDA da palha de trigo tratada com solução alcalina. Todavia, Sundstol (1984) afirmou que o efeito do tratamento químico na concentração de FDA não apresenta resultados consistentes. Por outro lado, o resíduo mineral deixado pelo hidróxido de sódio aumenta significativamente a matéria mineral e, como os resultados são expressos em percentuais, resulta em variação de outros componentes.

Observou-se efeito linear entre o nível de $\mathrm{NaOH}$ utilizado no tratamento químico e a concentração de hemicelulose, mas de pouca consistência, tendo em vista que o $\mathrm{R}^{2}$ é baixo, o que indica uma estimativa pouco eficiente e de baixa consistência. Este fato pode estar relacionado à estimativa da hemicelulose que, segundo Van Soest (1994) ao ser obtida pela diferença entre os teores de FDN e de FDA, pode trazer algumas imprecisões. Durante a extração do conteúdo celular e determinação da FDN, a hemicelulose pode ser superestimada pela recuperação de proteína da parede celular e precipitação de complexo de proteína-tanino, ou subestimada por dissolver pectina e considerar toda sílica solúvel. Quando da determinação da FDA, as imprecisões estão relacionadas à dissolubilidade da proteína complexada ou não, da quantidade de sílica recuperada e da precipitação parcial de pectina.

$\mathrm{O}$ efeito do tratamento químico com $\mathrm{NaOH}$ na DIVMS do feno de jurema-preta é ilustrado na Figura 1. Constatou-se aumento linear $(p<0,05)$ da DIVMS do feno de jurema-preta à medida que se elevou o teor de $\mathrm{NaOH}$ utilizado no tratamento químico. Embora o efeito linear tenha sido altamente significativo, é importante ressaltar que o $\mathrm{R}^{2}=0,6691$ pode ser considerado relativamente baixo; mesmo assim, a equação obtida pode ser utilizada, com moderada precisão, para estimar esta relação. Chaudhry (1997) ressaltou que, normalmente, a DIVMS de materiais tratados com solução alcalina apresenta relação linear positiva quando se usam níveis crescentes de $\mathrm{NaOH}$ até $8 \%$. Importante destacar que o $\mathrm{NaOH}$ vem sendo muito utilizado junto com outros compostos alcalinos e/ou com tratamento físico sob o argumento de ser um dos produtos químicos mais eficientes na deslignização dos compostos da parede celular das células vegetais.

O aumento da DIVMS do feno tratado com $\mathrm{NaOH}$ ocorreu devido à maior exposição dos componentes da parede celular, aumentando a suscetibilidade dos carboidratos estruturais à digestibilidade (Chaudhry, 1998), como também à remoção de compostos fenólicos, diminuindo a complexação de proteína e melhorando a digestibilidade "in vitro" (Akin et al., 1988), o que pode afetar a degradabilidade ruminal de FDN e de PB, principalmente de leguminosas ricas em tanino (Pereira Filho et al., 2001).

$\mathrm{Na}$ Figura 2, está ilustrada a relação do teor de tanino em função do nível de $\mathrm{NaOH}$ utilizado no tratamento químico do feno de jurema-preta. Os resultados indicaram que a concentração de tanino total na MS do feno de jurema-preta diminui linearmente $(\mathrm{p}<0,05)$ com o aumento de hidróxido de sódio na solução alcalina utilizado no tratamento químico,

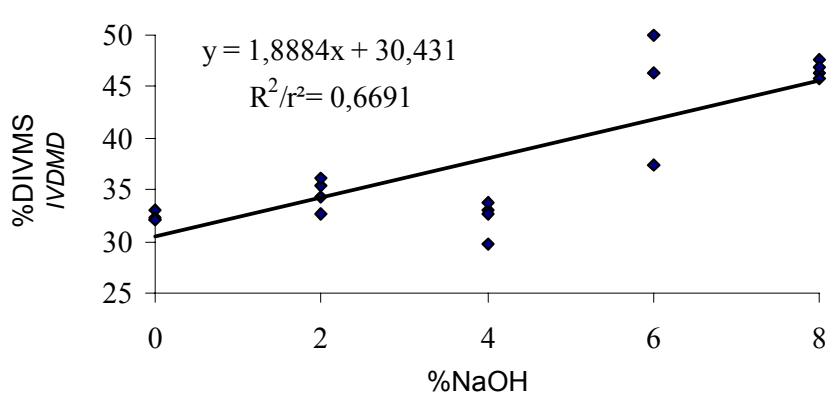

Figura 1 - Efeito do tratamento químico com $\mathrm{NaOH}$ na DIVMS do feno de jurema-preta.

Figure 1 - Effect of the chemical treatment with sodium hydroxide $(\mathrm{NaOH})$ on in vitro dry matter digestibility (IVDMD) of jurema-preta hay. 
proporcionando redução do teor de tanino em torno de $27 \%$. Este resultado foi considerado satisfatório, principalmente se associado aos benefícios ocorrentes em nível da parede celular, o que reflete diretamente na melhoria da digestibilidade do alimento.

Os compostos fenólicos, especialmente o tanino, têm por característica apresentar grupamentos de hidroxila reativos que, por sua vez, podem reagir com a extremidade carboxílica das proteínas (Schofield et al., 2001). Segundo Artz et al. (1987), a formação de camplexos tanino-proteína ocorrem principalmente através de pontes de hidrogênio e interações hidrofóbicas. A formação destes complexos varia em função do peso molecular, estrutura química e demais características do tanino e da proteína (Silanikove et al., 2001), o que pode refletir no nível adequado de tanino para proteção de proteína da ação de microrganismo no rúmen e boa disponibilidade no intestino (Loyola et al., 1999), fato observado por Loyola et al. (1998) ao avaliar o efeito do tanino no tratamento do farelo de canola.

A eficiência na determinação do teor de tanino varia principalmente em função da concentração de tanino na amostra, tipo de tanino (condensado, hidrossolúvel, ou total), do método utilizado, das características químicas do tanino e da proteína (Schofield et al., 2001), o que explica parcialmente a variabilidade dos resultados obtidos neste trabalho.

Existem vários métodos de determinação do teor de tanino, mas, face às dificuldades laboratoriais e ao objetivo da pesquisa, optou-se pelo método de Folin

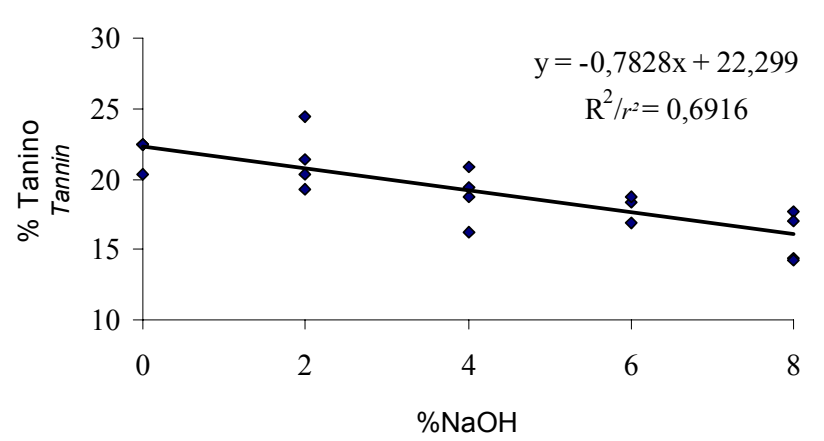

Figura 2 - Efeito do tratamento químico com $\mathrm{NaOH}$ na concentração de tanino do feno de jurema-preta.

Figure 2 - Effect of the treatment with sodium hydroxide $(\mathrm{NaOH})$ on tannin concentration of jurema-preta hay.
Denis (AOAC, 1995), que, segundo Perez et al. (1999), ao determinarem o teor de tanino de quatro variedades de sorgo por seis métodos, concluíram que, se for considerada a grande variabilidade entre os métodos e a praticidade laboratorial, o método de Folin Denis é o mais indicado para a determinação do tanino total.

Os resultados do tratamento químico com níveis crescentes de $\mathrm{NaOH}$ indicaram resposta linear positiva para DIVMS e linear negativa para teor de tanino, fato que se levou a avaliar a relação entre teor de tanino e a DIVMS, que é ilustrada na Figura 3. Foi verificada correlação negativa $(r=-0,55374 ; \mathrm{p}<0,0113)$ entre teor de tanino e DIVMS. Para a estimativa da DIVMS pelo teor de tanino, mesmo tendo apresentado significância, parece precipitado concluir algo sobre esta relação, tendo em vista o valor de $\mathrm{R}^{2}=$ 0,4302, indicando uma estimativa de baixa acurácia.

Como os taninos são classificados em hidrossolúvel e condensado, acredita-se que o conhecimento da DIVMS em função destas duas frações torna-se muito importante para entender-se os efeitos do tanino nas propriedades nutricionais dos alimentos, especialmente aqueles que apresentam alto teores de $\mathrm{PB}$ e de FDN, mas de baixa digestibilidade.

Pelos resultados obtidos, tem-se um indicativo de que o teor de tanino no feno de jurema-preta deve ser considerado em qualquer estimativa de DIVMS; considerações semelhantes foram relatadas por Mangan(1988) para plantas forrageiras de regiões semi-áridas e por Jasman (1993) para sementes de cereais e leguminosas.

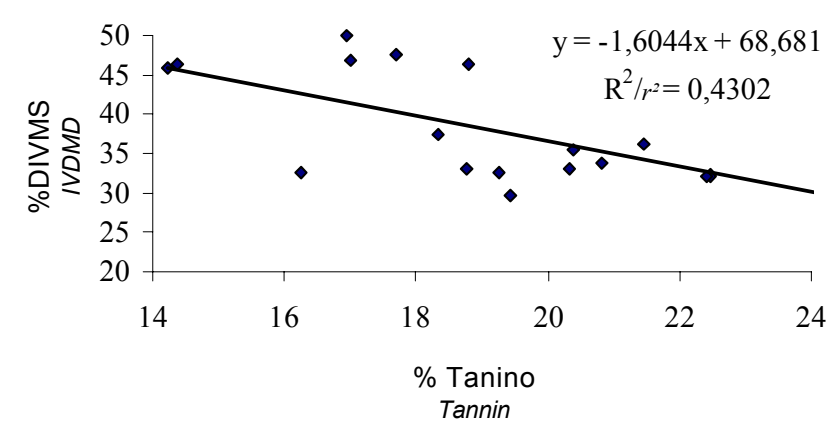

Figura 3 - Relação entre o teor de tanino e a DIVMS do feno de jurema-preta tratado com hidróxido de sódio.

Figure 3 - Relation between tannin concentration and in vitro dry matter digestibility (IVDMD) of jurema-preta hay treated with sodium hydroxide.

R. Bras. Zootec., v.32, n.1, p.70-76, 2003 


\section{Conclusões}

O tratamento químico com hidróxido de sódio influenciou na composição química do feno de juremapreta, reduzindo as concentrações de fibra em detergente neutro, de fibra em detergente ácido e de tanino.

O uso de hidróxido de sódio proporcionou aumento na digestibilidade in vitro da matéria seca do feno de jurema-preta.

\section{Literatura Citada}

AKIN, D.E.; RIGSBY, L.L.; THEODOROU, M.K. et al. Population changes of fibrolytic bacterium in the presence of phenolic acids and plant extracts. Animal Feed Science and Technology, v.19, p.261-275, 1988.

ANDRADE, J.B.; FERRARI JR., E.; BRAUN G. Valor nutritivo de cana-de-açúcar tratada com hidróxido de sódio e acrescida de rolão-de-milho. Pesquisa Agropecuária Brasileira, v.36, n.10, p.1265-1268, 2001.

ARAÚJO FILHO, J.A.; SILVA, N.L.; SOUSA, F.B.; CARVALHO, F. C. Pastagens no semi-árido: pesquisa para o desenvolvimento sustentável. In: REUNIÃO ANUAL DA SOCIEDADE BRASILEIRA DE ZOOTECNIA, 32., 1995, Brasília. Anais... Brasília: Sociedade Brasileira de Zootecnia, 1995. p.63-75.

ARTZ, W.E.; BISHOP, P.D.; DUNFER, A.K. et al. Interaction of synthetic proanthocyanidin dimer and trimer with bovine serum albumin and purified bean globulin fraction G-I. Journal of Agricultural and Food Chemistry, v.35, p.417-421, 1987.

ASSOCIATION OF OFFICIAL ANALYTICAL CHEMISTS AOAC, 1995. Official methods of analysis. 16. ed. Washington, D.C. 1995, 1298p.

CARVALHO FILHO, O.M.; SALVIANO, L.M. Evidências de ação inibidora da Jurema-Preta na fermentação "in vitro" de gramíneas forrageiras. Petrolina, PE, EMBRAPA/CPATSA, 1982，15p. (Circular Técnica EMBRAPA/CPATSA).

CHAUDHRY, A.S. Nutrient composition, digestion and rumen fermentation in sheep of wheat straw treated wich calcium oxide, sodium hydroxide and alkaline hydrogen peroxide. Animal Feed Science and Technology, v.74 p.315-328, 1998.

CHAUDHRY, A.S. Rumen degradation in sacco in sheep of wheat straw treated wich calcium oxide, sodium hydroxide and sodium hydroxide plus hydrogen peroxide. Animal Feed Science and Technology, v.83, p.313-323, 2000.

CHAUDHRY, A.S. Washing and filtration of wheat straw treated wich sodium hydroxide alone or wich hydrogen peroxide to modify cell wall composition and in vitro digestibility. Australian Journal of Experimental Agriculture, v.37, p.617-621, 1997.

JACKSON, M.G. Review article: the alkali treatment of straw. Animal Feed Science and Technology, v.2, n.2, p.105130, 1977.

JANSMAN, A.J.N. Tannins in feedstuffs for simple stomached animals. Nutrition Reseach Reviews, n.6, p.209-236, 1993.

KERLEY, M.S.; FAHEY JR.,G.C.; BERGER, L.L. et al. Effects of treating wheat straw with $\mathrm{pH}$-regulated solutions of alkaline hydrogen peroxide on nutrient digestion by sheep. Journal Dairy Science, v.70, p.2078-2084, 1987.

KLOPFENSTEIN, T.J. Chemical treatment of crops residues. Journal Animal Science, v.46, n.3, p.841-848, 1978.

LOYOLA, V.R.; SANTOS, G.T.; ZEOLA, L.N. et al. Degradabilidade in situ do farelo de canola tratado com calor e/ou tanino. Revista Brasileira de Zootecnia, v.28, n.3, p.598-604, 1999.

LOYOLA, V.R.; SANTOS, G.T.; ZEOLA, L.N. et al. Digestibilidade in vitro do farelo de canola tratado com calor e/ou tanino. Revista Brasileira de Zootecnia, v.27, n.5, p.1037-1041, 1998.

MADRID, J.; HERNÁNDEZ, F.; PULGAR, M.A. et al. Effects of citrus by-product suplementation on the intake and digestibility of urea + sodium hydroxide-treated barley straw in goats. Small Ruminant Research, v.28, p.241-248, 1998.

MANGAN, J.L. Nutritional effects of tannins in animal feeds. Nutrition Reseach Reviews, n.1, p.209-231, 1988.

MANZANO, R.P.; FUKUSHIMA, R.S.; GOMES, J.D.F. et al. Digestibilidade do bagaço de cana-de-açúcar tratado com reagentes químicos e pressão de vapor. Revista Brasileira de Zootecnia, v.29, n.4, p.1196-1204, 2000.

MOREIRA, V.R.; GONÇALVES, L.C.; CARMÉLIO, H. et al. Digestibilidade aparente da Brachiaria decumbens Stapt tratada com hidróxido de sódio, amônia anidra, ou misturada à Calotropis procera - 1. Matéria orgânica e balanço do nitrogênia. In: REUNIÃO ANUAL DA SOCIEDADE BRASILEIRA DE ZOOTECNIA, 33., 1996, Fortaleza. Anais... Fortaleza: Sociedade Brasileira de Zootecnia, 1996. p.327330.

NOLTE, M.E.; CLINE, J.H.; DEHORITY, B.A. et al. 1987. Treatment of wheat straw with alkaline solutions prepared from wood ashes to improve fiber utilization by ruminants. Journal Animal Science, v.64, p.1516-1528, 1987.

PEREIRA FILHO, J.M.; AMORIM, O.S.; SILVA, A.M.A. et al. Produção de matéria seca e de proteína bruta da juremapreta (Mimosa tenuiflora Wild). In: REUNIÃO ANUAL DA SOCIEDADE BRASILEIRA DE ZOOTECNIA, 36., 1999, Porto Alegre-RS. Anais... Porto Alegre: Sociedade Brasileira de Zootecnia, 1999. p.230-232.

PEREIRA FILHO, J.M.; AMORIM, O.S.; VIEIRA, E.L. et al. Efeito do tratamento químico com hidróxido de sódio sobre a degradabilidade "in situ" da FDN e da PB do feno de juremapreta (Mimosa tenuiflora Wild). In: REUNIÓN DA ASSOCIACIÓN LATINOAMÉRICANA DE PRODUCCIÓN ANIMAL, 17., 2001. Habana. Memorias... Habana-Cuba: Associación Latinoaméricana de Producción Animal, 2001. (CD Rom).

PEREZ, D.M.; MAIER, J.C.; BRUM, P.A.R. et al. Determinação do teor de tanino de quatro variedades de sorgo por intermédio de métodos quantitativos. Revista Brasileira de Zootecnia, v.28, n.3, p.453-458, 1999.

REED, J.D. Nutritional toxicology of tannins and related polyphenols and forage legumes. Journal Animal Science, v.73, n.5, p.1516-1528, 1995.

REIS, R.A.; RODRIGUES, L.R.A.; PEDROSO, P. Avaliações de fontes de amônia para o tratamento de volumosos. Revista Brasileira de Zootecnia, v.24, n.4, p.486-493, 1995.

STATISTICAL ANALYSIS SYSTEM - SAS. User's guide. 6.ed. Cary: 1999. 956p.

SCHOFIELD, P.; MBUGUA, D.M.; PELL, A.N. Analysis of condensed tannins: a review. Animal Feed Science and Technology, v.91, p.21-40, 2001. 
SILANIKOVE, N.; PEREVOLOTSKY, A.; PROVENZA, F.D. Use of tannin-binding to assay for tannins and their negative postingestive effects in ruminants. Animal Feed Science and Technology, v.91, p.68-81, 2001.

SILVA, J.D. Análises de alimentos: métodos químicos e biológicos. Viçosa - MG: Universidade Federal de Viçosa, 1998. $154 \mathrm{p}$.

SUNDSTOL, F. Ammonia treatment of straw: methods for treatment and feeding experience in Norway. Animal Feed Science and Technology, v.10, n.2, p.173-184, 1984.

TARKOV, H.; FEIST, W.C. A mechanism for improving the digestibility of lignocelulosic materials wich dilute alkali and liquid ammonia. Advances in Chemistry Series., v.95, n.1, p.197-218, 1969.

VAN SOEST, P.J. Nutritional ecology of the ruminant. Ney York: Cornell University Press, 1994. 476p.
VASCONCELOS, V.R. Caracterização química e degradação de forrageiras do semi-árido brasileiro no rúmem de caprinos. Jaboticabal: Universidade Estadual Paulista, 1997. 86p. Tese (Doutorado em Zootecnia) - Universidade Estadual Paulista, 1997.

VIEIRA, E.L.; SILVA, A.M.A.; COSTA, R.G. et al. Valor nutritivo do feno de espécies lenhosas da caatinga. In: REUNIÃO ANUAL DA SOCIEDADE BRASILEIRA DE ZOOTECNIA, 35., 1998, Botucatu. Anais... Botucatu Sociedade Brasileira de Zootecnia, 1998. p.227-229.

Recebido em: 19/02/02

Aceito em: 21/08/02 